\title{
High oxygen pressure single crystal growth of highly Ca-doped spin ladder compound $\mathrm{Sr}_{14-x} \mathrm{Ca}_{x} \mathrm{Cu}_{24} \mathrm{O}_{41}(x>12)$
}

\author{
Guochu Deng a,*, D. Mohan Radheep ${ }^{\mathrm{b}}$, R. Thiyagarajan ${ }^{\mathrm{b}}$, Ekaterina Pomjakushina ${ }^{\mathrm{a}}$, \\ Shuang Wang ${ }^{\mathrm{a}}$, Neda Nikseresht ${ }^{\mathrm{c}}$, S. Arumugam ${ }^{\mathrm{b}}$, Kazimierz Conder ${ }^{\mathrm{a}}$ \\ a Laboratory for Developments and Methods, Paul Scherrer Institute, $\mathrm{CH}-5232$ Villigen, Switzerland \\ ${ }^{\mathrm{b}}$ Center for High Pressure Research, School of Physics, Bharathidasan University, Tiruchirappalli 620 024, India \\ ${ }^{\mathrm{c}}$ Laboratory for Quantum Magnetism, École Polytechnique Fédérale de Lausanne, CH-1015 Lausanne, Switzerland
}

\section{A R T I C L E I N F O}

Article history:

Received 17 March 2011

Accepted 8 April 2011

Communicated by K. Jacobs

Available online 16 April 2011

\section{Keywords}

A1. Incommensurate

A2. Floating zone

A2. High pressure crystal growth

B1. Cuprates

B2. Superconductor

B2. Spin ladder

\begin{abstract}
A B S T R A C T
Large size high-quality Ca-doped $\mathrm{Sr}_{14-x} \mathrm{Ca}_{x} \mathrm{Cu}_{24} \mathrm{O}_{41}(x=12.2,12.6$ and 13) spin ladder superconducting single crystals were grown using a modified mirror floating zone furnace with oxygen pressure up to 35 bar. The qualities of the as-grown single crystals were confirmed by polarized optical microscopy, neutron diffraction and X-ray diffraction methods. The sample compositions and homogeneity were measured using micro-X-ray fluorescence spectroscopy. The lattice parameters of each sample have been refined using the Rietveld method. The oxygen stoichiometry measurements which were performed by hydrogen reduction/thermogravimetry method show that all the three samples are slightly oxygen deficient even though high oxygen pressure was applied during growth. The high oxygen pressure is indispensible for growing highly Ca-doped $\mathrm{Sr}_{14-x} \mathrm{Ca}_{x} \mathrm{Cu}_{24} \mathrm{O}_{41}$ single crystals. The susceptibility was measured along $c$-axis for all three compositions, fitting well with the one dimensional dimer model, consistent with the reported values of undoped $\mathrm{Sr}_{14} \mathrm{Cu}_{24} \mathrm{O}_{41}$ parent compounds.
\end{abstract}

(c) 2011 Elsevier B.V. All rights reserved.

\section{Introduction}

Ca-doped $\mathrm{Sr}_{14-x} \mathrm{Ca}_{x} \mathrm{Cu}_{24} \mathrm{O}_{41}$ is a spin $=1 / 2$ magnetic system, which includes both spin chains and ladders configurations observed in the $\mathrm{CuO}_{2}$ and $\mathrm{Cu}_{2} \mathrm{O}_{3}$ layers, respectively, in the structure. Many interesting phenomena such as spin dimerization [1], charge density wave [2], holes crystallization [3], etc. have been observed in this system, raising an intensive research interests on this topic. The most striking phenomenon observed in these materials is an appearance of superconductivity in highly Ca-doped compounds $(x \geq 11.5)$ under high hydrostatic pressure ( $>3 \mathrm{GPa}$ ) [4]. Since this is the first and the only superconductor with a quasi-one-dimensional spin ladder structure, it is very important to investigate the origin of superconductivity in these materials. In order to clarify the correlation between superconductivity and the spin gap behavior on the ladder, various experiments such as nuclear magnetic resonance [5], inelastic neutron scattering [6] and so on have been done under ambient and elevated pressures [7]. Even though such great amount of efforts haves been made on these materials, the knowledge in this system is still limited due to discrepancies in the data obtained by different methods and/or different groups. This can be to some

\footnotetext{
* Corresponding author. Tel.: +410563103562.

E-mail addresses: guochu.deng.cn@gmail.com, guochu.deng@psi.ch (G. Deng).
}

extend understood because the structure of this compound is very complex with incommensurate chain and ladder sublattices [8]. Additionally high-quality large size single crystals of highly Ca-doped compounds $(x>12)$ were not grown up to now. Large size high-quality $\mathrm{Sr}_{14-x} \mathrm{Ca}_{x} \mathrm{Cu}_{24} \mathrm{O}_{41}$ single crystal samples are necessary for experiments such as inelastic neutron scattering. The highest Ca-content $\mathrm{Sr}_{14-x} \mathrm{Ca}_{x} \mathrm{Cu}_{24} \mathrm{O}_{41}$ single crystal $(x=12)$ was grown using floating zone method by Vanishri et al. [9] at oxygen pressure of 12 bar. However, the applied pressure of 12 bar was the limit of typical mirror floating zone furnace. For further increase of Ca content $(x>12)$ in $\mathrm{Sr}_{14-x} \mathrm{Ca}_{x} \mathrm{Cu}_{24} \mathrm{O}_{41}$, higher oxygen pressures are indispensible to synthesize pure phases of these materials. For example, 400 bar oxygen pressure was applied to synthesize powder samples with up to now the highest Ca content $(x=13.6)$ [4]. Generally, high oxygen pressure synthesis has been widely used to increase the oxygen stoichiometry in oxides, enhance the oxidization valence states of transition metals, extend the solubility of dopants in certain solid solutions, and stabilize certain structures. In most of the cases high pressure synthesis could only be used to prepare powder samples or small single crystals because of experimental problems [10]. On the other hand, traveling solvent floating zone (TSFZ) method can be used to grow $\mathrm{cm}^{3}$-size large crystals. However, in a commercial TSFZ furnaces the gas pressure is limited to $10 \mathrm{bar}$, which does not allow to grow $\mathrm{Sr}_{14-x} \mathrm{Ca}_{x} \mathrm{Cu}_{24} \mathrm{O}_{41}$ single crystals with $x>12$ [9,11]. 
Until now, reported high pressure ( $>15$ bar) TSFZ crystal growth experiments were performed for growing $\mathrm{CuO}$ single crystal and investigating the $\mathrm{CoCu}_{2} \mathrm{O}_{3}$ phase diagram $[12,13]$.

For this study, we modified our commercial TSFZ furnace to provide a stable crystal growth environment in a chamber filled with high pressure gas up to 35 bar. With this modified furnace, a series of highly Ca-doped $\mathrm{Sr}_{14-x} \mathrm{Ca}_{x} \mathrm{Cu}_{24} \mathrm{O}_{41}$ single crystals with $x=12.2,12.6$ and 13 were grown at 15,27 and 35 bar oxygen pressure, respectively. Crystal growth of the highly Ca-doped $\mathrm{Sr}_{1.8} \mathrm{Ca}_{12.2} \mathrm{Cu}_{24} \mathrm{O}_{41}, \mathrm{Sr}_{1.4} \mathrm{Ca}_{12.6} \mathrm{Cu}_{24} \mathrm{O}_{41}$ and $\mathrm{SrCa}_{13} \mathrm{Cu}_{24} \mathrm{O}_{41}$ single crystal samples with a volume of several $\mathrm{cm}^{3}$, is here reported for the first time.

\section{Experimental procedures}

To grow single crystals of $\mathrm{Sr}_{14-x} \mathrm{Ca}_{x} \mathrm{Cu}_{24} \mathrm{O}_{41}$ with $x>12$, oxygen pressure higher than 10 bar should be applied during the growth procedure, which exceeds limitation of commercial optical floating zone furnaces. Hence, we have modified our crystal growth optical furnace (Model: FZ-T-10000-HVI-VP-PC, Crystal Systems Corp. Japan) in a way to work alternatively at elevated or standard pressures. In order to increase pressure in the crystal growth chamber, the quartz tube surrounding the crystal during growth (originally $50 \mathrm{~mm}$ diameter and $5 \mathrm{~mm}$ wall thickness) was replaced with another one of a smaller diameter and thicker wall ( $30 \mathrm{~mm}$ and $7.5 \mathrm{~mm}$, respectively). Metal flanges adapters have to be additionally prepared to mount a tube of a smaller diameter. High pressure pipes and gauges by passing the standard tubing were added. They were completely separated from the system when standard pressures were used during crystal growth. The upper and lower shafts diameters were reduced (from $20 \mathrm{~mm}$ down to $11 \mathrm{~mm}$ ) in order to diminish the "pushing" force created by the gas pressure in the chamber. The modified system has been tested at room temperature with pressures up to 40 bar. It has to be noted that in the "high pressure" set-up the initial alignments of the feed and seed rods is essentially important for the crystal growth since the quartz tube inside diameter becomes very close to those of the rods. The $\mathrm{SrCa}_{13} \mathrm{Cu}_{24} \mathrm{O}_{41}$ crystals were successfully grown in one week with $63.2 \%$ power of four $300 \mathrm{~W}$ halogen lamps at 35 bar, indicating a stable high pressure situation at high temperature during the long-term crystal growth procedure.

For single crystal growth experiments, the starting polycrystalline materials were prepared by a solid state reaction. High purity raw materials of $\mathrm{SrCO}_{3}$ (Alfa Aesar 99.994\%), $\mathrm{CaCO}_{3}$ (Alfa Aesar 99.997\%) and CuO (Alfa Aesar 99.9999\%) were weighted and mixed thoroughly according to the nominal stoichiometry $\mathrm{Sr}_{14-x} \mathrm{Ca}_{x} \mathrm{Cu}_{24} \mathrm{O}_{41}(x=12.2,12.6,13)$. Another batch of powders was prepared with a final $(\mathrm{SrO}+\mathrm{CaO}): \mathrm{CuO}$ molar ratio equal 3:7, which was used for preparation of the seed rods. Both batches of powders were annealed at $850(48 \mathrm{~h}), 900(16 \mathrm{~h}), 940(16 \mathrm{~h}){ }^{\circ} \mathrm{C}$ with intermediate grindings, in order to make them homogenous. The synthesized powders were finally pressed into rods with a diameter around $8 \mathrm{~mm}$ using hydrostatic press under pressure of $4 \mathrm{kbar}$, and then annealed at $950^{\circ} \mathrm{C}$ for $15 \mathrm{~h}$.

The crystal with nominal composition $\mathrm{Sr}_{1.8} \mathrm{Ca}_{12.2} \mathrm{Cu}_{24} \mathrm{O}_{41}$ was grown using four $300 \mathrm{~W}$ halogen lamps with a power of $57.8 \%$ at a static 15 bar oxygen pressure. In all the performed experiments, just after the melting temperature was reached and the seed and feed rods were connected, the mirrors were moved down $(\sim 6 \mathrm{~mm})$ in order to force predominate melting of the seed rod which was prepared to be $\mathrm{CuO}$-rich in comparison with the grown compound. This is in accordance with the phase diagram [14] showing that $\mathrm{Sr}_{14} \mathrm{Cu}_{24} \mathrm{O}_{41}$ should be in equilibrium below peritectic temperature with $\mathrm{CuO}$-rich liquid. After a fast initial growth stage with a rate of $2 \mathrm{~mm} / \mathrm{h}$, the final growth rate was stabilized at $1 \mathrm{~mm} / \mathrm{h}$. During the whole crystal growth procedure, the feed and seed rods rotated with a rate of $16 \mathrm{rpmn}$ in opposite directions.

The $\mathrm{Sr}_{1.4} \mathrm{Ca}_{12.6} \mathrm{Cu}_{24} \mathrm{O}_{41}$ crystals were grown at $62.6 \%$ of $300 \mathrm{~W}$ lamp power at a static 27 bar oxygen pressure with a final growth rate $1 \mathrm{~mm} / \mathrm{h}$. The lamp power was around $5 \%$ higher than the value used for growing of $\mathrm{Sr}_{1.8} \mathrm{Ca}_{12.2} \mathrm{Cu}_{24} \mathrm{O}_{41}$ probably mainly due to higher convective heat losses.

The growth of $\mathrm{SrCa}_{13} \mathrm{Cu}_{24} \mathrm{O}_{41}$ crystals was performed at the highest oxygen pressure of 35 bar and $63.2 \%$ lamp power with a lower growth rate of $0.7 \mathrm{~mm} / \mathrm{h}$, keeping all the other growth conditions unchanged.

The as-grown single crystal samples were cut and polished perpendicular to the growth direction and the optical homogeneity of the polished surface was checked by using optical polarizing microscope. The composition mapping of $\mathrm{Sr}_{1.4} \mathrm{Ca}_{12.6} \mathrm{Cu}_{24} \mathrm{O}_{41}$ and $\mathrm{SrCa}_{13} \mathrm{Cu}_{24} \mathrm{O}_{41}$ single crystals has been carried out to check the composition homogeneity using X-ray fluorescence spectroscopy (XRF, Orbis Micro-XRF Analyzer, EDAX) on the polished cross-section surfaces. An appropriate calibration was done before the XRF analysis which guarantied $\sim 2 \%$ absolute measurement accuracy. The reproducibility of the method was much higher, around $0.2 \%$. Oxygen stoichiometry of all the three as-grown crystals were measured by the hydrogen reduction using a thermogravimetric analyzer (Model: TG 449 F3 Jupiter ${ }^{\circledR}$ TGA-Thermogravimetric Analyzer, NETZSCH). The hydrogen reduction experiments were performed for powderized single crystal samples $(\sim 50 \mathrm{mg})$ in a $30 \mathrm{ml} / \mathrm{min}$ flow of $\mathrm{H}_{2}-\mathrm{He}$ mixed gas $\left(5 \% \mathrm{H}_{2}+95 \% \mathrm{He}\right)$ with a heating rate $2-5{ }^{\circ} \mathrm{C} / \mathrm{min}$ up to 850 or $950^{\circ} \mathrm{C}$.

Selected parts of the as-grown crystals were ground, and the powder samples were mounted on a flat revolving sample holder. The powder X-ray diffraction was performed using $\mathrm{Cu} K_{\alpha 1}$ radiation $(\lambda=1.5406 \AA)$ on the diffractometer D8 (Brucker).

Crystallographic perfection of the $\mathrm{Sr}_{1.8} \mathrm{Ca}_{12.2} \mathrm{Cu}_{24} \mathrm{O}_{41}$ and $\mathrm{Sr}_{1.4} \mathrm{Ca}_{12.6} \mathrm{Cu}_{24} \mathrm{O}_{41}$ crystals was checked by neutron diffraction on 2-axes neutron diffractometer Morpheus with wavelength $\lambda=5.02 \AA$ at Paul Scherrer Institute. The rocking curve of the $\mathrm{SrCa}_{13} \mathrm{Cu}_{24} \mathrm{O}_{41}$ single crystal was measured using Seifert PTS 300 Diffractometer in Paul Scherrer Institute. Temperature-dependent susceptibility measurements were performed in a SQUID magnetometer (Cryogenic Ltd.) or PPMS system (Quantum Design) on all three single crystals with a magnetic field along $c$-axis.

\section{Results and discussion}

Fig. 1 shows the picture of the as-grown $\mathrm{Sr}_{1.8} \mathrm{Ca}_{12.2} \mathrm{Cu}_{24} \mathrm{O}_{41}$ single crystal boule and the polished cross-section surfaces under optical polarizing microscope. Comparing cross-sections (b) and (c), single phase could be obtained after quite a long time growth $(\sim 50 \mathrm{~h})$ even though there exist still a few crystallographically differently oriented domains. The top $30 \mathrm{~mm}$ of the boule was found to be single domain in the grown single crystal. According to Ammerahl et al. [11], $\mathrm{Sr}_{2} \mathrm{Ca}_{12} \mathrm{Cu}_{24} \mathrm{O}_{41}$ single crystal can only be grown as a pure phase with a very slow growth rate of $\sim 0.8 \mathrm{~mm} / \mathrm{h}$ and oxygen pressure of 12 bar. Here, we have successfully grown $\mathrm{Sr}_{1.8} \mathrm{Ca}_{12.2} \mathrm{Cu}_{24} \mathrm{O}_{41}$ single crystals with growth rate of $1 \mathrm{~mm} / \mathrm{h}$ under the pressure of 15 bar oxygen atmosphere.

Fig. 2(a) shows the as-grown $\mathrm{Sr}_{1.4} \mathrm{Ca}_{12.6} \mathrm{Cu}_{24} \mathrm{O}_{41}$ single crystal boule of the length over $80 \mathrm{~mm}$. It was observed that after $20 \mathrm{~h}$ of growth ( $\sim 25 \mathrm{~mm}$ of the length) of the crystal, outward appearance become elliptical with two shiny faces on the sidewall. This growth habit was consistent with the observation in the modestly Ca-doped single crystals by Ammerahl et al. [11]. The $c$-axis of the 


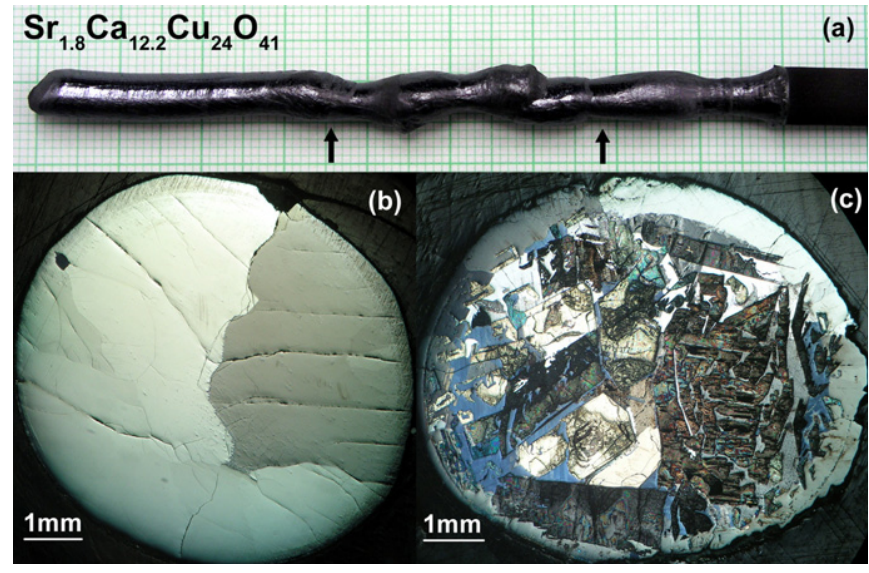

Fig. 1. As-grown $\mathrm{Sr}_{1.8} \mathrm{Ca}_{12.2} \mathrm{Cu}_{24} \mathrm{O}_{41}$ crystal boule (a) and the polished crosssections at the position $5.5 \mathrm{~cm}$ (b) and $2 \mathrm{~cm}$ (c) away from the bottom.

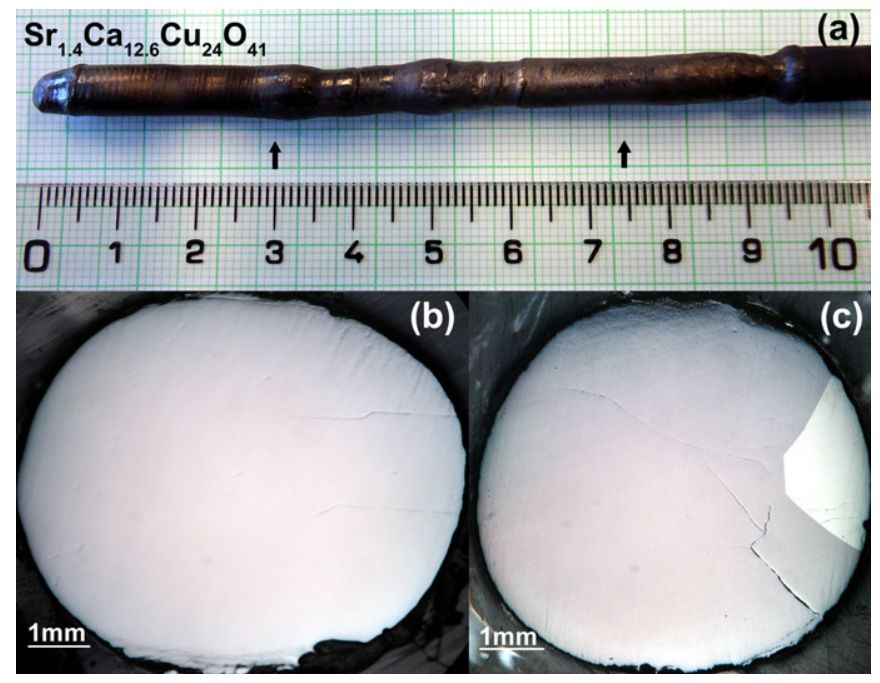

Fig. 2. As-grown $\mathrm{Sr}_{1.4} \mathrm{Ca}_{12.6} \mathrm{Cu}_{24} \mathrm{O}_{41}$ crystal boule (a) and the polished crosssections of the boule at the position $3 \mathrm{~cm}$ (b) and $6.5 \mathrm{~cm}$ (c) away from the bottom.

crystals was found to be almost parallel to the vertical growth direction, and $b$-axis is perpendicular to the shiny faces, which is the shorter axis of the ellipse, consistent with the previous report [11]. Fig. 2b and c show the photographs of the polished crosssections using polarized light at the positions indicated by the arrows marked in the figures. Fig. 2c shows two domains under polarized light, a large one of nearly $95 \%$ of the cross-section area and a very small one, indicating the initial grain selection had been almost completed and a large monodomain crystal is extending over nearly the whole boule volume. The cross-section made at $\sim 65 \mathrm{~mm}$ from the beginning of the growth (Fig. 2b) shows a homogeneous picture, which did not contain any observable impurities, minority phase inclusions, grain boundaries, etc.

The single crystal with the highest Ca content, which was successfully grown in these series of experiments, is $\mathrm{SrCa}_{13} \mathrm{Cu}_{24} \mathrm{O}_{41}$. The obtained crystal boule, grown under 35 bar oxygen pressure with a slow growth rate $(0.7 \mathrm{~mm} / \mathrm{h})$, is shown in Fig. 3a. As one can see in Fig. $3 \mathrm{~b}$ and c, only two domains are observed after a growth length of $\sim 40 \mathrm{~mm}$. Finally, the sample grew into a single domain on the top of the crystal $\sim 30 \mathrm{~mm}$ in length. To grow the highest Ca content of this series of the sample with slower growth rate of $0.7 \mathrm{~mm} / \mathrm{h}$ was critical and successful. It seems critical for growing this compound since another crystal growth trial, which was made on $\mathrm{Sr}_{1.1} \mathrm{Ca}_{12.9} \mathrm{Cu}_{24} \mathrm{O}_{41}$ with a similar pressure but a slightly fast growth rate $(1 \mathrm{~mm} / \mathrm{h})$ failed. However, attempts to grow $\mathrm{Sr}_{1.1} \mathrm{Ca}_{12.9} \mathrm{Cu}_{24} \mathrm{O}_{41}$ crystals with the

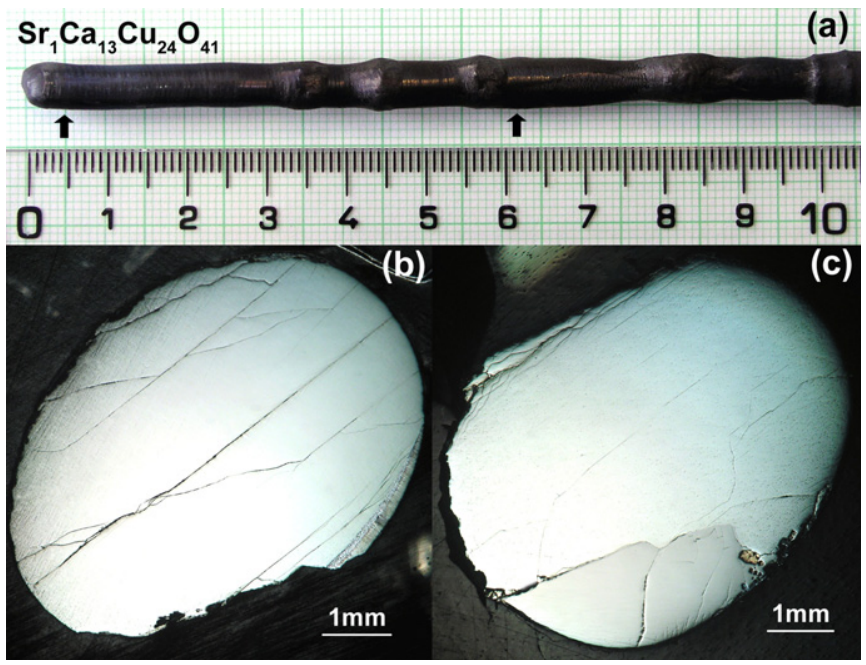

Fig. 3. As-grown $\mathrm{SrCa}_{13} \mathrm{Cu}_{24} \mathrm{O}_{41}$ crystal boule (a) and the polished cross-sections at the position $0.5 \mathrm{~cm}$ (b) and $6 \mathrm{~mm}$ (c) away from the top.

similar oxygen pressure (34 bar) with slightly higher growth rate $(1 \mathrm{~mm} / \mathrm{h})$ failed.

Figs. 4 and 5 show the Micro-XRF composition mappings of the cross-sections of the $\mathrm{Sr}_{1.4} \mathrm{Ca}_{12.6} \mathrm{Cu}_{24} \mathrm{O}_{41}$ and $\mathrm{SrCa}_{13} \mathrm{Cu}_{24} \mathrm{O}_{41}$ single crystals, which were made for, respectively, selected $0.8 \times 1 \mathrm{~mm}^{2}$ and $2.4 \times 3 \mathrm{~mm}^{2}$ areas of the polished samples as shown in Figs. 2 and 3. The Micro-XRF results shown in Fig. 4 were obtained in the area containing two different domains. The X-ray diffraction mapping shown in the inset of Fig. 4 exhibits two areas of different contrasts, while the compositions of $\mathrm{Sr}, \mathrm{Ca}$ and $\mathrm{Cu}$ are homogeneous, indicating that they are the same phase of different domains. The Micro-XRF mapping of $\mathrm{Sr}$, $\mathrm{Ca}$ and $\mathrm{Cu}$ shown in Fig. 5 is a proof of homogeneous elemental distribution in a quite large area. The homogeneity on both sides of the crack indicates that the crack may be due to the cleavage of one single domain taking place during cooling. The results of composition analysis performed by Micro-XRF are summarized in Table 1.

Fig. 6 shows typical thermogravimetric curves obtained during the hydrogen reduction $\left(5 \% \mathrm{H}_{2}\right.$ in $\left.\mathrm{He}\right)$ of the powderized $\mathrm{Sr}_{1.8} \mathrm{Ca}_{12.2} \mathrm{Cu}_{24} \mathrm{O}_{41}, \mathrm{Sr}_{1.4} \mathrm{Ca}_{12.6} \mathrm{Cu}_{24} \mathrm{O}_{41}$ and $\mathrm{SrCa}_{13} \mathrm{Cu}_{24} \mathrm{O}_{41}$ single crystal samples. For all these samples, the reduction process took place below $600{ }^{\circ} \mathrm{C}$ but sustained until $800{ }^{\circ} \mathrm{C}$. The total mass losses during the experiment were $14.93 \%, 15.25 \%$ and $15.21 \%$ for $\mathrm{Sr}_{1.8} \mathrm{Ca}_{12.2} \mathrm{Cu}_{24} \mathrm{O}_{41}, \mathrm{Sr}_{1.4} \mathrm{Ca}_{12.6} \mathrm{Cu}_{24} \mathrm{O}_{41}$ and $\mathrm{SrCa}_{13} \mathrm{Cu}_{24} \mathrm{O}_{41}$ samples, respectively. It was assumed that the products of the reductions are $\mathrm{SrO}, \mathrm{CaO}, \mathrm{Cu}$ and water. Therefore, the measured weight-losses of $14.93 \%, 15.25 \%$ and $15.21 \%$ correspond to the following content: $\mathrm{Sr}_{1.8} \mathrm{Ca}_{12.2} \mathrm{Cu}_{24} \mathrm{O}_{40.30}, \mathrm{Sr}_{1.4} \mathrm{Ca}_{12.6} \mathrm{Cu}_{24} \mathrm{O}_{40.83}$ and $\mathrm{SrCa}_{13} \mathrm{Cu}_{24} \mathrm{O}_{40.44}$, respectively. It was found that reproducibility of the $\mathrm{TG} / \mathrm{H}_{2}$ analysis was \pm 0.03 in $\delta$. It is worthwhile to note that $\mathrm{Sr}_{1.4} \mathrm{Ca}_{12.6}$ $\mathrm{Cu}_{24} \mathrm{O}_{40.83}$ has oxygen content close to stiochiometry, much higher than those found in the other two. This may suggest that 15 and 35 bar were sufficient to stabilize the phase of $\mathrm{Sr}_{1.8} \mathrm{Ca}_{12.2} \mathrm{Cu}_{24} \mathrm{O}_{41}$ and $\mathrm{SrCa}_{13} \mathrm{Cu}_{24} \mathrm{O}_{41}$, respectively, but not sufficient to get fully oxidized material while 27 bar oxygen pressure seems to be high enough to fully oxidize $\mathrm{Sr}_{1.4} \mathrm{Ca}_{12.6} \mathrm{Cu}_{24} \mathrm{O}_{41}$. Ammerahl et al. [11] found that $\mathrm{Sr}_{3} \mathrm{Ca}_{11} \mathrm{Cu}_{24} \mathrm{O}_{41-\delta}$ can be stabilized under a minimal oxygen pressure of 8 bar. Our $\mathrm{Sr}_{3} \mathrm{Ca}_{11} \mathrm{Cu}_{24} \mathrm{O}_{41-\delta}$ crystal, which was grown in 12 bar oxygen (much higher than 8 bar), have a quite small $\delta$ value $(\sim 0.2)$. This fact supports the above speculation and indicates that $\delta$ is quite dependent on the oxygen pressure during the crystal growth. The large $\delta$ value $(0.56)$ in $\mathrm{SrCa}_{13} \mathrm{Cu}_{24} \mathrm{O}_{41-\delta}$ hints that $x=13$ is nearly the highest Ca content which can be reached under 35 bar. These results also confirm the relationship 

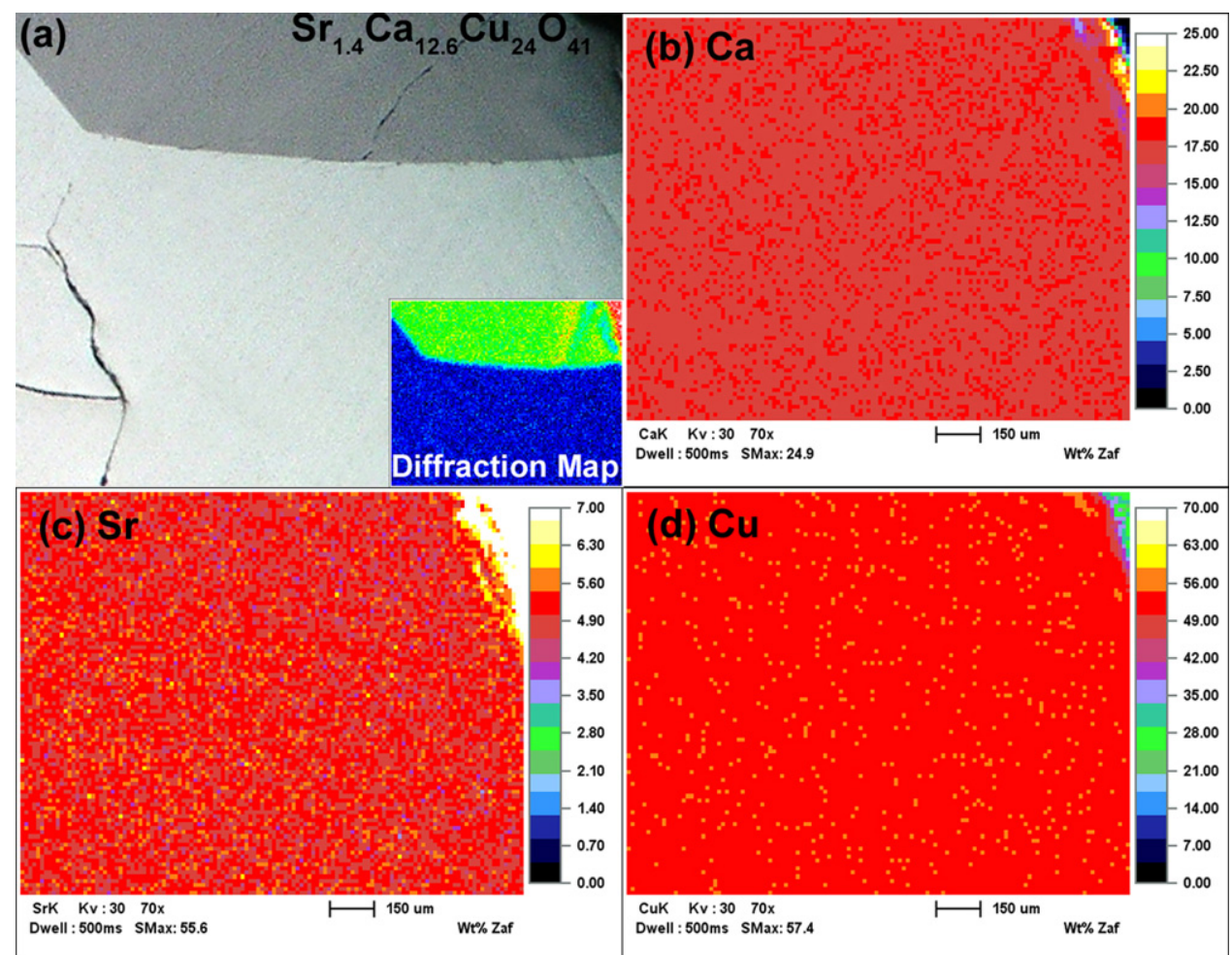

Fig. 4. (a) Optical microscopic image of the polished $\mathrm{Sr}_{1.4} \mathrm{Ca}_{12.6} \mathrm{Cu}_{24} \mathrm{O}_{41}$ crystal. The inset shows the X-ray diffraction mapping. (b), (c) and (d) show the mappings of Ca, $\mathrm{Sr}$ and $\mathrm{Cu}$ weights in the area of $(\mathrm{a})$, respectively.
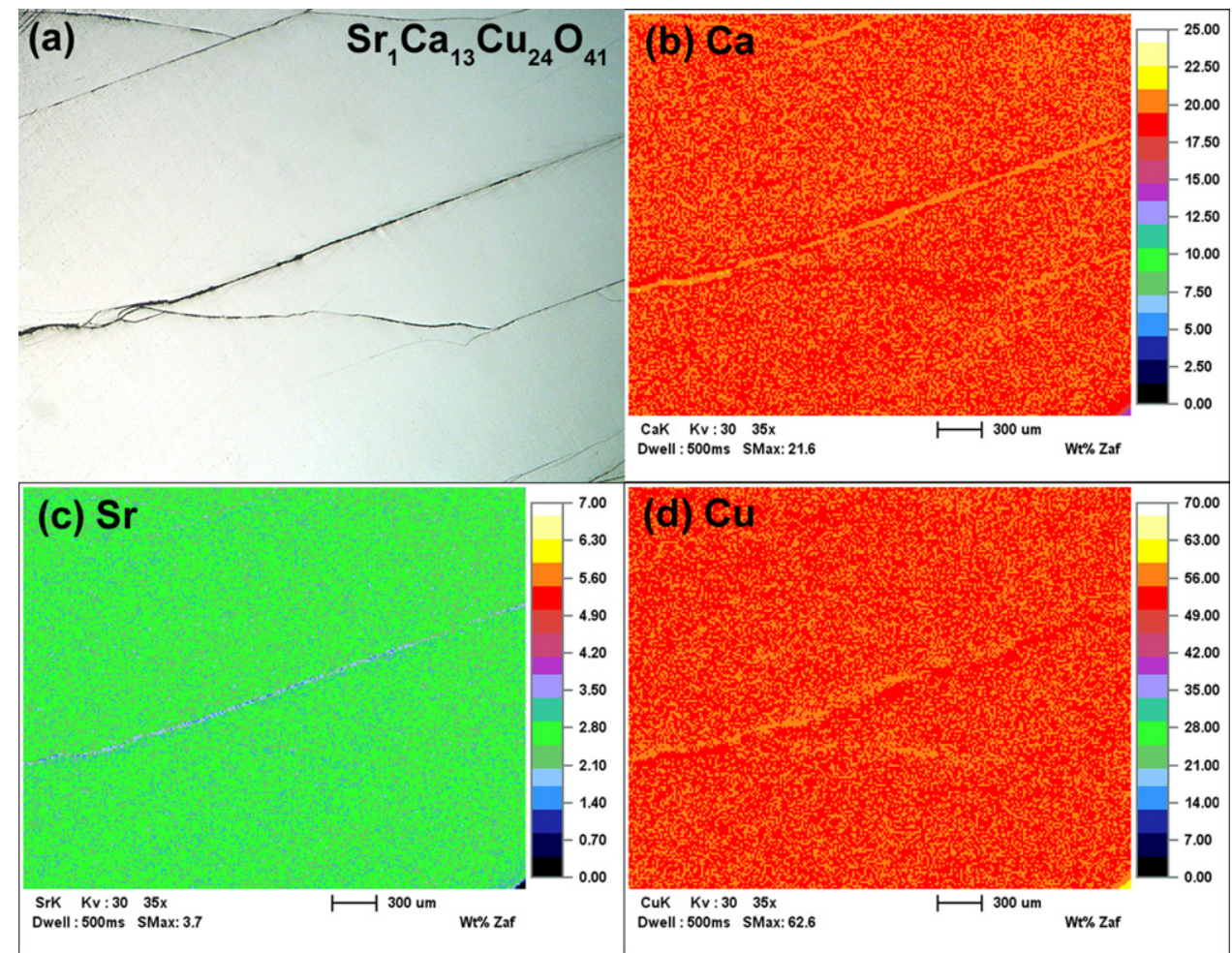

Fig. 5. (a) Optical microscopic image of the polished $\mathrm{SrCa}_{13} \mathrm{Cu}_{24} \mathrm{O}_{41}$ crystal; (b), (c) and (d) show the mappings of $\mathrm{Ca}$, $\mathrm{Sr}$ and $\mathrm{Cu}$ weights in the area of (a), respectively.

between oxygen pressure for crystal growth and the Ca content in these compounds.

Since neutrons have much deeper penetration depth than X-ray, neutron diffraction is a perfect tool to characterize the quality of single crystal samples. The top parts of the $\mathrm{Sr}_{1.8} \mathrm{Ca}_{12.2} \mathrm{Cu}_{24} \mathrm{O}_{41}$ and $\mathrm{Sr}_{1.4} \mathrm{Ca}_{12.6} \mathrm{Cu}_{24} \mathrm{O}_{41}$ single crystals were studied by neutron diffraction method. The rocking curve of the Bragg peak (0014; average structure index) are shown in Fig. 7a and b, for both compositions, 
respectively. The curves show nearly perfect shape without any shoulders and FWHM of around $0.3^{\circ}$, proving the excellent quality of the as-grown crystals. The rocking curve of the $\mathrm{SrCa}_{13} \mathrm{Cu}_{24} \mathrm{O}_{41}$ single crystal was measured by using X-ray diffractometer and shown in Fig. 4c. The FWHM is around $0.1^{\circ}$, also indicating good quality of the crystal sample.

X-ray powder diffraction patterns were measured on the powderized samples from the top parts of the as-grown crystals with different compositions. The diffraction patterns of $\mathrm{Sr}_{1.8} \mathrm{Ca}_{12.2} \mathrm{Cu}_{24} \mathrm{O}_{41}, \mathrm{Sr}_{1.4} \mathrm{Ca}_{12.6} \mathrm{Cu}_{24} \mathrm{O}_{41}$ and $\mathrm{SrCa}_{13} \mathrm{Cu}_{24} \mathrm{O}_{41}$ were shown in Fig. 8. As shown in the inset of Fig. 8, the (0400) peaks are shifted to high angles with the increase of the Ca content, indicating the $\mathrm{Ca}$ incorporation in the $\mathrm{Sr}_{14-x} \mathrm{Ca}_{x} \mathrm{Cu}_{24} \mathrm{O}_{41}$ lattice,

Table 1

Crystal compositions determined by Micro-XRF.

\begin{tabular}{llllll}
\hline Nominal formula & $\mathrm{Sr}(\mathrm{at} \%)$ & $\mathrm{Ca}(\mathrm{at} \%)$ & $\mathrm{Cu}$ (at\%) & $\mathrm{O}$ (at\%) & Formula \\
\hline $\mathrm{Sr}_{1.4} \mathrm{Ca}_{12.6} \mathrm{Cu}_{24} \mathrm{O}_{41}$ & 2.12 & 15.78 & 30.10 & 52.00 & $\mathrm{Sr}_{1.6} \mathrm{Ca}_{12.5} \mathrm{Cu}_{23.8} \mathrm{O}_{41.1}$ \\
$\mathrm{SrCa}_{13} \mathrm{Cu}_{24} \mathrm{O}_{41}$ & 1.17 & 17.08 & 30.00 & 51.75 & $\mathrm{Sr}_{0.9} \mathrm{Ca}_{13.5} \mathrm{Cu}_{23.7} \mathrm{O}_{40.9}$ \\
\hline
\end{tabular}

and it can be clearly seen in the sample with the highest Ca content. The crystal structure of spin ladder compounds is composed of two incommensurate subsystems, namely, $\mathrm{CuO}_{2}$ chain and $(\mathrm{Sr}, \mathrm{Ca})_{2} \mathrm{Cu}_{2} \mathrm{O}_{3}$ ladder subsystem. Therefore, all XRD patterns from the single crystal samples were fitted with the Rietveld method. This refinement was done in a four-dimensional $(3+1)$ formalism using JANA2006 [15] by introducing a modulated composite model (spacegroup Xmmm $(00 \gamma) s s 0$, equivalent to Fmmm $(0,0,1+\gamma) s s 0$ superspace group in International Tables for Crystallography 9.8.3.2 [16], where $X$ means nonconventional centering [17]). The structure refinement was made independently from results of chemical analysis i.e. without introducing fixed occupancies at the metal sites. However, the refined occupancies of $\mathrm{Sr}$ and $\mathrm{Ca}$ are very close to the measured results. As an example, the experimental and refined results for $\mathrm{SrCa}_{13} \mathrm{Cu}_{24} \mathrm{O}_{41}$ are shown in Fig. 9. The red curve indicated the calculated data, the colorful bars below the diffraction curve, consisting of red, green, blue and orange bars, indicated the calculated Bragg positions from the different sublattices or the satellites. An excellent fit of the data without any detectable impurity phases within the accuracy of the measurement was obtained. The obtained fit is

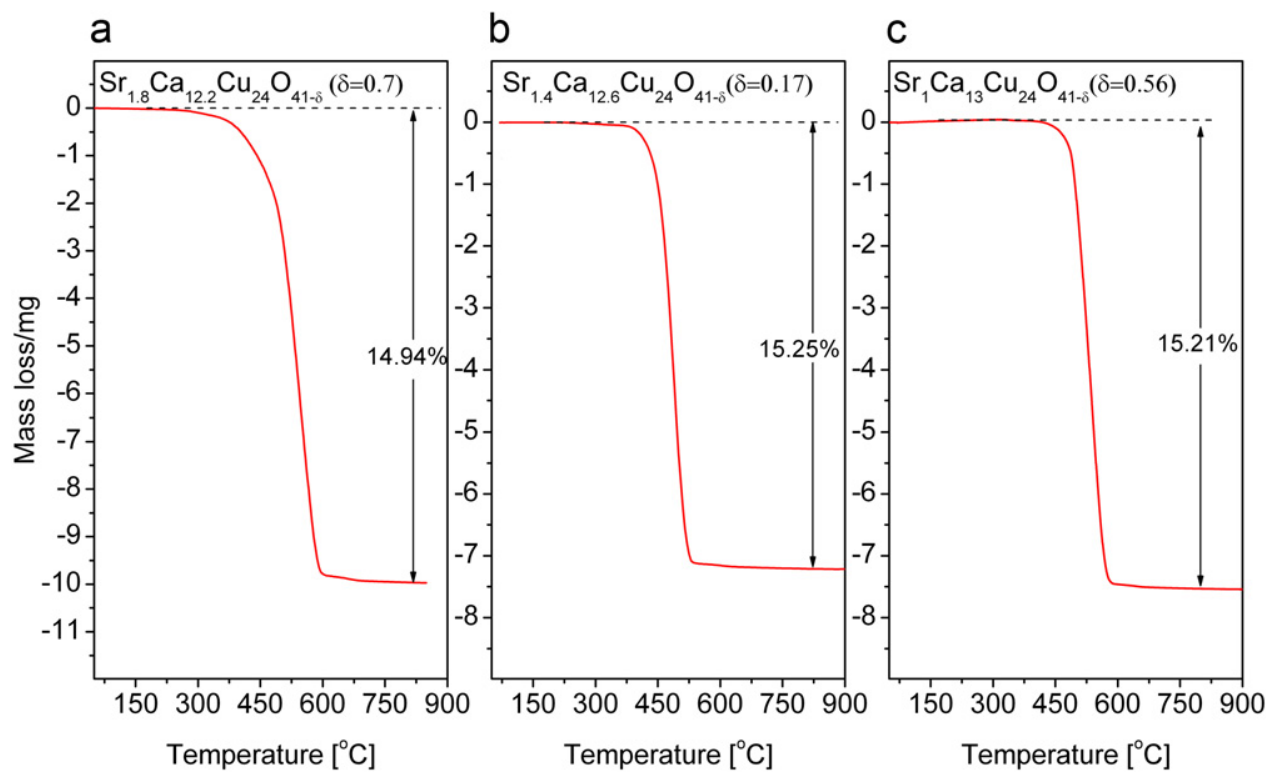

Fig. 6. Weight losses of the $\mathrm{Sr}_{1.8} \mathrm{Ca}_{12.2} \mathrm{Cu}_{24} \mathrm{O}_{41}, \mathrm{Sr}_{1.4} \mathrm{Ca}_{12.6} \mathrm{Cu}_{24} \mathrm{O}_{41}$ and $\mathrm{SrCa}_{13} \mathrm{Cu}_{24} \mathrm{O}_{41}$ powderized single crystal samples in the hydrogen reduction experiments.

a

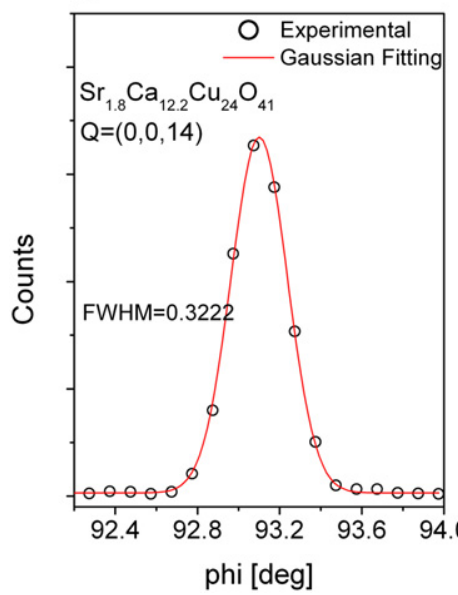

b

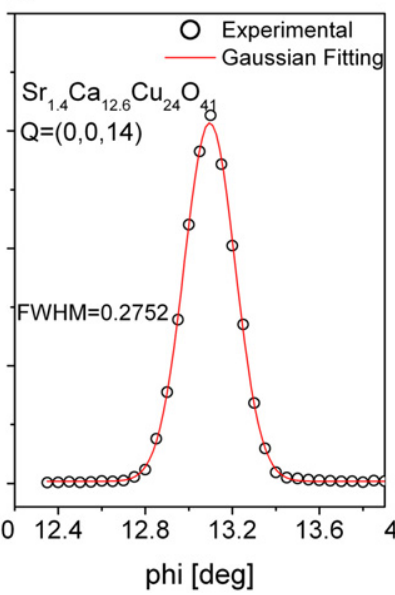

C

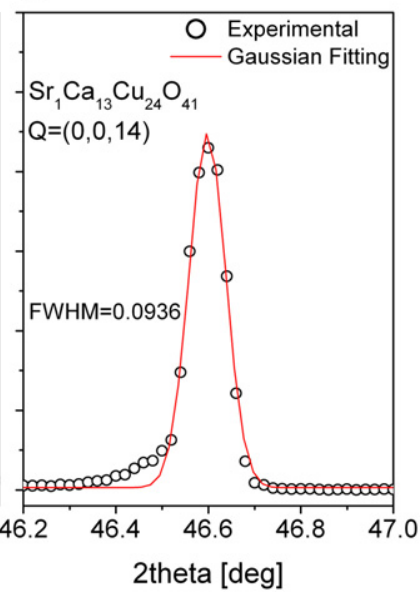

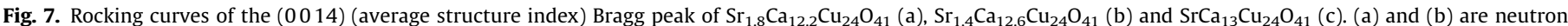
diffraction data, and (c) is X-ray diffraction data. 
much better than those reported previously [18]. The refined structural parameters for these three compositions are listed in Table 2. All these refined data is in good agreement with the data obtained for the powder sample of $\mathrm{Sr}_{0.4} \mathrm{Ca}_{13.6} \mathrm{Cu}_{24} \mathrm{O}_{41}$ [8]. It is interesting to note that all the lattice parameters shrink as the increase of Ca doping. Our neutron diffraction investigation on the low and moderate $\mathrm{Ca}$-doped $\mathrm{Sr}_{14-x} \mathrm{Ca}_{x} \mathrm{Cu}_{24} \mathrm{O}_{41}$ show that the $c_{C}$ (the $c$-axis of the chain sublattice) extended by increasing $\mathrm{Ca}$

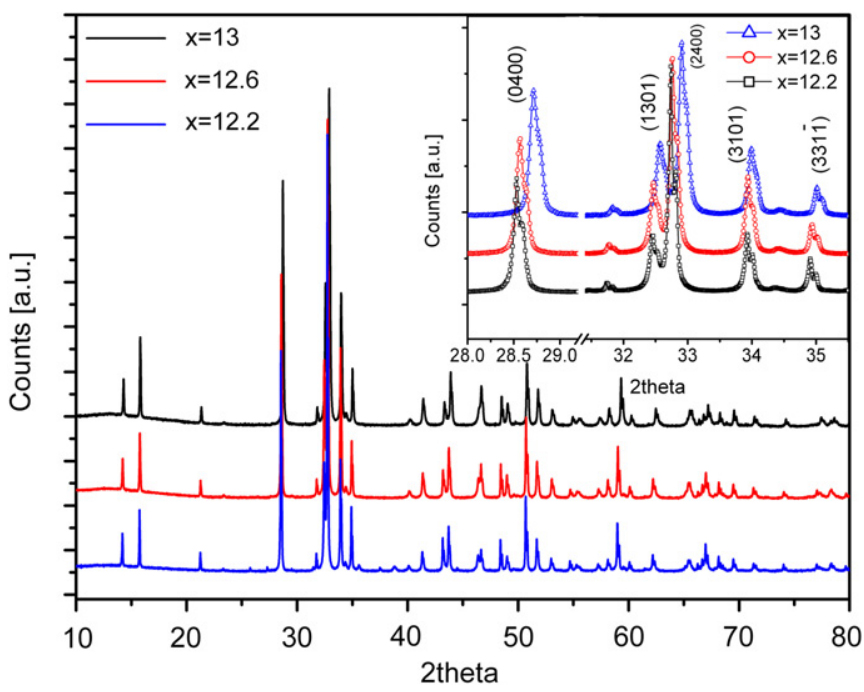

Fig. 8. $\mathrm{X}$-ray powder diffraction patterns of $\mathrm{Sr}_{1.8} \mathrm{Ca}_{12.2} \mathrm{Cu}_{24} \mathrm{O}_{41}, \mathrm{Sr}_{1.4} \mathrm{Ca}_{12.6} \mathrm{Cu}_{24} \mathrm{O}_{41}$ and $\mathrm{SrCa}_{13} \mathrm{Cu}_{24} \mathrm{O}_{41}$ powderized samples. The inset is the magnified main Bragg peaks.

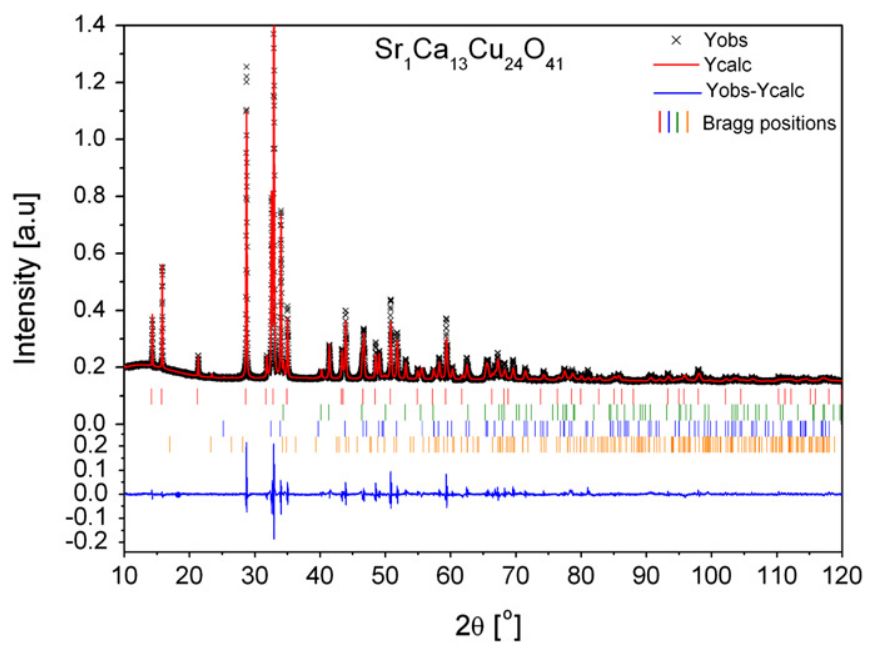

Fig. 9. Observed (black crosses) and refined (red curve) X-ray powder diffraction patterns of the powderized $\mathrm{SrCa}_{13} \mathrm{Cu}_{24} \mathrm{O}_{41}$ single crystal sample. The red, green, blue and orange bars (from top to bottom) below the patterns mark the Bragg peak positions for the common ( $h k 00)$, ladder $(h k l 0)$, chain $(h k 0 m)$ and satellite $(h \mathrm{klm})$ diffractions, respectively (for interpretation of the references to color in this figure legend, the reader is referred to the web version of this article). doping in the range of $x<11$ [19]. Thus, this abnormal trend was changed into opposite way in the range of $x>12$. Another important feature for these highly Ca-doped samples is that the ratio between $c_{\mathrm{C}} / c_{\mathrm{L}}$ (the $c$ axes of chain and ladder sublattices, respectively) is around 0.705 , which is larger than the value of 0.7 for the undoped parent compound (Fig. 10).

Temperature dependence of the DC magnetic susceptibility of single crystal samples were measured with a field of $0.5 \mathrm{~T}$ applied along $c$-axis. As shown in Fig. 8, the susceptibility curves show a broad bump at $70 \mathrm{~K}$, and bend slightly down below $70 \mathrm{~K}$, and then quickly increase at lower temperature. This tendency is consistent with those observed in undoped $\mathrm{Sr}_{14} \mathrm{Cu}_{24} \mathrm{O}_{41}$ sample. The measured susceptibility of each compound can be well fitted using one dimensional dimer model, resulting in exchange interaction $J_{\mathrm{D}}$, number of dimer per formula $N_{\mathrm{D}}$, number of free spin per formula $N_{\mathrm{F}}$, etc. listed in Table 3 . As we can see that the highest Ca sample have the best fitting with $J_{\mathrm{D}}=138 \mathrm{~K}$, and $2 N_{\mathrm{D}}+N_{\mathrm{F}}=3.18$, which are close to the reported fitting values in $\mathrm{Sr}_{14} \mathrm{Cu}_{24} \mathrm{O}_{41}$ [20]. This indicates that $\mathrm{Ca}$ substitution in this sample does not

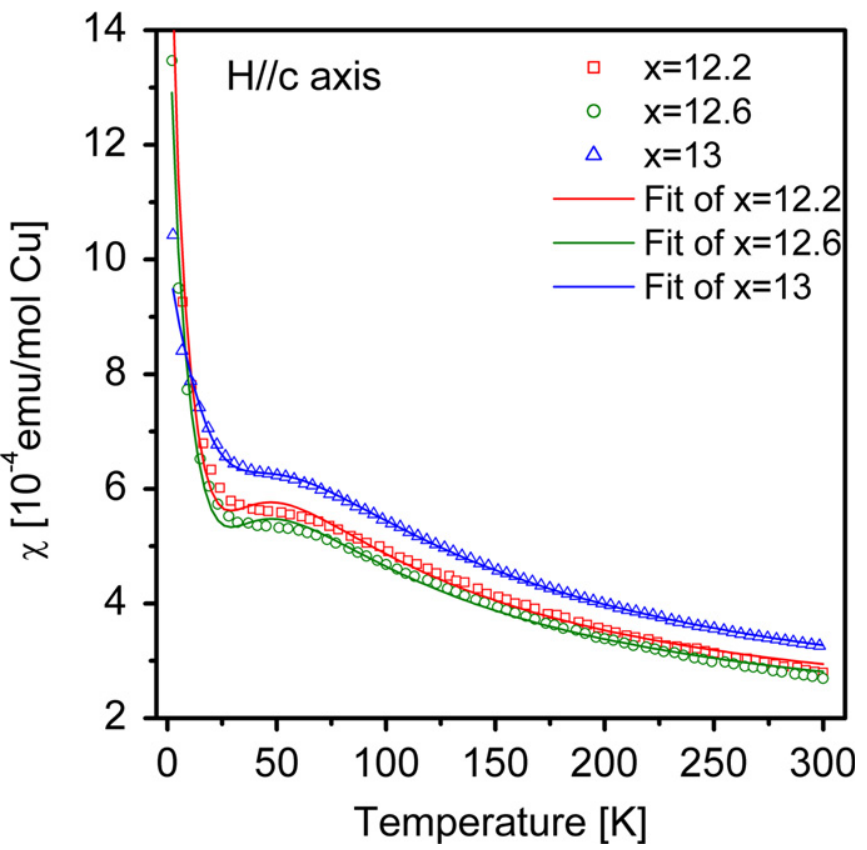

Fig. 10. Temperature dependence of susceptibility of $\operatorname{Sr}_{1.8} \mathrm{Ca}_{12.2} \mathrm{Cu}_{24} \mathrm{O}_{41}$ $\mathrm{Sr}_{1.4} \mathrm{Ca}_{12.6} \mathrm{Cu}_{24} \mathrm{O}_{41}$ and $\mathrm{SrCa}_{13} \mathrm{Cu}_{24} \mathrm{O}_{41}$ single crystals with magnetic fields applied parallel to $c$-axis.

Table 3

Parameters fitting susceptibility results with the dimer model.

\begin{tabular}{llllll}
\hline$x$ & $J_{\mathrm{D}}$ & \multicolumn{1}{l}{$\theta$} & \multicolumn{1}{l}{$N_{\mathrm{F}}$} & \multicolumn{1}{l}{$N_{\mathrm{D}}$} & $2 N_{\mathrm{D}}+N_{\mathrm{F}}$ \\
\hline 12.2 & 110.26629 & -5.83128 & 0.5649 & 0.9138 & 2.3925 \\
12.6 & 112.06556 & -7.43451 & 0.5704 & 0.8672 & 2.3048 \\
13 & 138.61346 & -32.98342 & 1.4993 & 0.8413 & 3.1819 \\
\hline
\end{tabular}

Table 2

Structure refinement results with X-ray powder diffractions of the three crystal samples.

\begin{tabular}{|c|c|c|c|c|c|c|c|c|}
\hline Sample & $a$ & $b$ & $c_{c}$ & $c_{1}$ & $q$ & GOF & $R_{\mathrm{p}}$ & $R \mathrm{w}_{\mathrm{p}}$ \\
\hline $\mathrm{Sr}_{1.8} \mathrm{Ca}_{12.2} \mathrm{Cu}_{24} \mathrm{O}_{41}$ & 11.2819 & 12.5259 & 2.7494 & 3.8940 & 0.706055 & 2.41 & 2.21 & 3.25 \\
\hline $\mathrm{Sr}_{1.4} \mathrm{Ca}_{12.6} \mathrm{Cu}_{24} \mathrm{O}_{41}$ & 11.2750 & 12.5160 & 2.7454 & 3.8952 & 0.704822 & 2.65 & 2.39 & 4.31 \\
\hline $\mathrm{SrCa}_{13} \mathrm{Cu}_{24} \mathrm{O}_{41}$ & 11.2640 & 12.4597 & 2.7455 & 3.8928 & 0.705280 & 3.20 & 2.07 & 3.40 \\
\hline
\end{tabular}


substantially change the spin gap of the chain. However, for the other two samples the fitting was not perfect, resulting in lower $J_{\mathrm{D}}$ values. Since both $J_{\mathrm{D}}$ values are smaller than the reported one in $\mathrm{Sr}_{14} \mathrm{Cu}_{24} \mathrm{O}_{41}$, and the oxygen deficiency in these two samples are quite different, this reduction of $\mathrm{J}_{\mathrm{D}}$ should not be attributed to the different oxygen content, which was previously proposed [20]. This can be related to the doping concentration of either $\mathrm{Sr}$ or $\mathrm{Ca}$ because this deviation was also detected in the doped samples like $x=3,7$ and 11 but not in samples with $x=0$ and 13 according to our measurements in these samples.

\section{Conclusion}

Large size single crystal of $\mathrm{Sr}_{1.8} \mathrm{Ca}_{12.2} \mathrm{Cu}_{24} \mathrm{O}_{41}, \mathrm{Sr}_{1.4} \mathrm{Ca}_{12.6} \mathrm{Cu}_{24} \mathrm{O}_{41}$ and $\mathrm{SrCa}_{13} \mathrm{Cu}_{24} \mathrm{O}_{41}$ were successfully grown using modified high pressure traveling floating zone method. Experiments demonstrate that 35 bar oxygen pressure can be maintained for a long-term single crystal growth procedure efficiently stabilizing the high-Ca phase during the growth. The as-grown crystal was found to be of high quality by polarized optical microscopy, Micro-XRF, neutron and X-ray diffraction. The oxygen stoichiometrics of $\mathrm{Sr}_{14-x} \mathrm{Ca}_{x}$ $\mathrm{Cu}_{24} \mathrm{O}_{41}$ crystals were determined to be $40.30,40.73$ and 40.44 for $x=12.2,12.6$ and 13 , respectively. The magnetic susceptibilities of all these samples were measured, showing typical singlet ground state features at low temperature and consistent with the reported results in the undoped parent compound.

\section{Acknowledgments}

We are grateful to Dr. Andreas Wittkopp at EDAX Business Unit, AMETEK GmbH in Germany for the Micro-XRF measurement. The authors gratefully acknowledge the financial support from the Indo-Swiss Joint Research Program (ISJRP, Contract no. JRP122960) by Swiss State Secretariat of Education and Research. The author (S. Arumugam) would like to thank the Department of Science and Technology and UGC, New Delhi, for the financial support. Magnetometry was supported by SNF.

\section{References}

[1] M. Matsuda, K. Katsumata, Observation of a dimerized state in the $S=1 / 2$ quasi-one-dimensional antiferromagnet $\mathrm{Sr}_{14} \mathrm{Cu}_{24} \mathrm{O}_{41}$, Phys. Rev. B 53 (1996) 12201-12205

[2] G. Blumberg, P. Littlewood, A. Gozar, B.S. Dennis, N. Motoyama, H. Eisaki, S. Uchida, Sliding density wave in $\mathrm{Sr}_{14} \mathrm{Cu}_{24} \mathrm{O}_{41}$ ladder compounds, Science 297 (2002) 584-587.
[3] P. Abbamonte, G. Blumberg, A. Rusydi, A. Gozar, P.G. Evans, T. Siegrist L. Venema, H. Eisaki, E.D. Isaacs, G.A. Sawatzky, Crystallization of charge holes in the spin ladder of $\mathrm{Sr}_{14} \mathrm{Cu}_{24} \mathrm{O}_{41}$, Nature 431 (2004) 1078-1081.

[4] M. Uehara, T. Nagata, J. Akimitsu, H. Takahashi, N. Mori, K. Kinoshita, Superconductivity in the ladder material $\mathrm{Sr}_{0.4} \mathrm{Ca}_{13.6} \mathrm{Cu}_{24} \mathrm{O}_{41.84}$, J. Phys. Soc Jpn. 65 (1996) 2764-2767.

[5] K. Kumagai, S. Tsuji, M. Kato, Y. Koike, NMR study of carrier doping effects on spin gaps in the spin ladder $\mathrm{Sr}_{14-x} \mathrm{~A}_{x} \mathrm{Cu}_{24} \mathrm{O}_{41}(\mathrm{~A}=\mathrm{Ca}, \mathrm{Y}$, and La), Phys. Rev. Lett. 78 (1997) 1992-1995.

[6] L.P. Regnault, J.P. Boucher, H. Moudden, H. Moudden, J.E. Lorenzo, A. Hiess, U. Ammerahl, G. Dhalenne, A. Revcolevschi, Spin dynamics in the magnetic chain arrays of Sr14CU24041: a neutron inelastic scattering investigation, Phys. Rev. B 59 (1999) 1055-1059.

[7] H. Mayaffre, P. Auban-Senzier, M. Nardone, D. Jerome, D. Poilblanc C. Bourbonnais, U. Ammerahl, G. Dhalenne, A. Revcolevschi, Absence of a spin gap in the superconducting ladder compound $\mathrm{Sr}_{2} \mathrm{Ca}_{12} \mathrm{Cu}_{24} \mathrm{O}_{41}$, Science 279 (1998) 345-348.

[8] M. Isobe, T. Ohta, M. Onoda, F. Izumi, S. Nakano, J.Q. Li, Y. Matsui, E. Takayama-Muromachi, T. Matsumoto, H. Hayakawa, Structural and electrical properties under high pressure for the superconducting spin-ladder system $\mathrm{Sr}_{0.4} \mathrm{Ca}_{13.6} \mathrm{Cu}_{24} \mathrm{O}_{41+\delta}$, Phys. Rev. B 57 (1998) 613-621.

[9] S. Vanishri, C. Marin, H.L. Bhat, B. Salce, D. Braithwaite, L.P. Regnault, Crystal growth and characterization of two-leg spin ladder compounds: $\mathrm{Sr}_{14} \mathrm{Cu}_{24} \mathrm{O}_{41}$ and $\mathrm{Sr}_{2} \mathrm{Ca}_{12} \mathrm{Cu}_{24} \mathrm{O}_{41}$, J. Cryst. Growth 311 (2009) 3830-3834.

[10] J. Karpinski, G.I. Meijer, H. Schwer, R. Molinski, E. Kopnin, K. Conder, M. Angst J. Jun, S. Kazakov, A. Wisniewski, R. Puzniak, J. Hofer, V. Alyoshin, A. Sin, High-pressure synthesis, crystal growth, phase diagrams, structural and magnetic properties of $\mathrm{Y}_{2} \mathrm{Ba}_{4} \mathrm{Cu}_{n} \mathrm{O}_{2 n+x}, \mathrm{HgBa}_{2} \mathrm{Ca}_{n-1} \mathrm{Cu}_{n} \mathrm{O}_{2 n+2+\delta}$ and quasione-dimensional cuprates, Supercond. Sci. Technol. 12 (1999) R153-R181.

[11] U. Ammerahl, G. Dhalenne, A. Revcolevschi, J. Berthon, H. Moudden, Crystal growth and characterization of the spin-ladder compound $(\mathrm{Sr}, \mathrm{Ca})_{14} \mathrm{Cu}_{24} \mathrm{O}_{41}$ J. Cryst. Growth 193 (1998) 55-60.

[12] G. Behr, W. Loser, M.O. Apostu, W. Gruner, M. Hucker, L. Schramm, D. Souptel, A. Teresiak, J. Werner, Floating zone growth of $\mathrm{CuO}$ under elevated oxygen pressure and its relevance for the crystal growth of cuprates, Cryst. Res. Technol. 40 (2005) 21-25.

[13] N. Wizent, L. Schramm, G. Behr, W. Loser, W. Gruner, A. Voss, B. Buchner L. Schultz, Phase diagram features and solidification behaviour of $\mathrm{CoCu}_{2} \mathrm{O}_{3}$ at elevated oxygen pressure, J. Solid State Chem. 182 (2009) 2036-2040.

[14] W. Wong-Ng, L.P. Cook, W. Greenwood, Melting of $\mathrm{Sr}_{14} \mathrm{Cu}_{24} \mathrm{O}_{41}$ at oxygen pressures of $0.0075,0.021$ and $0.1 \mathrm{MPa}$, Physica C: Superconductivity 299 (1998) 9-14.

[15] M. Dušek, et al., Advances in solution of modulated structures reflected by Jana system, J. Phys.: Conf. Ser. 226 (2010) 012014.

[16] T. Janssen, A. Janner, A. Louijenga-Vos, P.M.d. Wolff, Incommensurate and commensurate modulated structures, in: International Tables for Crystallography, vol. C, 2006, pp. 907-955 (Chapter 9.8).

[17] I. Orlov, L. Palatinus, G. Chapuis, From space to superspace and back: superspace Group Finder, J. Appl. Crystallogr. 41 (2008) 1182-1186.

[18] A.F. Jensen, F.K. Larsen, B.B. Iversen, V. Petricek, T. Schultz, Y. Gao, Importance of true satellite reflections in the analysis of modulated, composite crystal structures, 1: a new refinement of $\left[\mathrm{M}_{2} \mathrm{Cu}_{2} \mathrm{O}_{3}\right]_{7+\delta}\left[\mathrm{CuO}_{2}\right]_{10}, \mathrm{M}=\mathrm{Bi}_{0.06} \mathrm{Sr}_{0.46}$ $\mathrm{Ca}_{0.48}$, Acta Crystallogr. B 53 (1997) 113-124.

[19] G. Deng, V. Pomjakushin, V. Petricek, E. Pomjakushina, M. Kenzelmann, K. Conder, Structural evolution of one-dimensional spin ladder compounds $\mathrm{Sr}_{14-x} \mathrm{Ca}_{x} \mathrm{Cu}_{24} \mathrm{O}_{41}$ with $\mathrm{Ca}$ doping and related hole redistribution evidence, Phys. Rev. B, submitted.

[20] Z. Hiroi, S. Amelinckx, G. VanTendeloo, N. Kobayashi, Microscopic origin of dimerization in the $\mathrm{CuO}_{2}$ chains in $\mathrm{Sr}_{14} \mathrm{Cu}_{24} \mathrm{O}_{41}$, Phys. Rev. B 54 (1996) 15849-15855. 